\title{
Investigation On Mechanism of Ultrasonic Welding AZ31B / 5052 Joint With Laser Texturing On Mental Surface
}

\section{Cailing Wang}

Shanghai University of Engineering Science

Yanfeng Xing ( $\nabla$ xyf2001721@163.com)

Shanghai University of Engineering Science

Jingyao $\mathrm{Hu}$

Shanghai University of Engineering Science

Junding Luo

Shanghai NIO Automobile Co.Ltd,

Sheng Zeng

Shanghai NIO Automobile Co.Ltd,

\section{Research Article}

Keywords: ultrasonic welding, laser texture, surface contact , connect mechanism

Posted Date: December 17th, 2021

DOI: https://doi.org/10.21203/rs.3.rs-1151412/v1

License: (c) (1) This work is licensed under a Creative Commons Attribution 4.0 International License. Read Full License

Version of Record: A version of this preprint was published at The International Journal of Advanced Manufacturing Technology on April 18th, 2022. See the published version at https://doi.org/10.1007/s00170-022-09203-2. 
Article

\title{
Investigation on mechanism of ultrasonic welding AZ31B / 5052 joint with laser texturing on mental surface
}

\author{
Cailing Wang ${ }^{1}$, Yanfeng Xing1,** ,Jingyao $\mathrm{Hu}^{1}{ }^{1}$ Junding $\mathrm{Luo}^{2}$ and Sheng Zeng2
}

1 School of Mechanical and Automotive Engineering, Shanghai University of Engineering Science, Shanghai 201620, China; 13697062506@163.com(C.W.), xyf2001721@163.com(Y.X.) ,hjy0790@163.com(J.H)

2 Shanghai NIO Automobile Co.Ltd,shanghai 201805,China; junding.luo@nio.com(J.L.),

sheng.zeng@nio.com(S.Z.)

* Correspondence: xyf2001721@163.com

\begin{abstract}
The ultrasonic welding was carried out to improve the quality of dissimilar $\mathrm{Al} / \mathrm{Mg}$ alloys joint. The effects of laser texturing on the microstructure and mechanism of AZ31B/5052 joint connected by ultrasonic welding were also investigated. A series of laser texturing experiments on $\mathrm{Al}$ alloy (5052) and $\mathrm{Mg}$ alloy (AZ31B) were performed to determine the process parameters and their effect on ultrasonic weld quality, especially on weld strength. Little effect was attained by optimizing welding parameters in improving mechanical properties. Both welding parameters and different texture pattern were investigated to obtain good weld quality. The connection mechanisms of joints were discussed based on the analysis of weld interface morphology, microstructure evolution. Mechanical analysis of particle and movement of material atoms were analyzed in the study to explain the connect mechanism. The results show that the better lock-interface and lager lap shear strength were attained by laser texture addition and optimal welding parameters. Compared with the untextured joint, swirling bonding interface was obtained after the laser texture. The laser texture with grid pattern was found to raise the strength up to $26 \%$ higher maximum tensile-shear load than the joints obtained with the untextured surface.
\end{abstract}

Keywords: ultrasonic welding; laser texture; surface contact ; connect mechanism

\section{Introduction}

Energy conservation and emission reduction have deep-rooted in normal daily life and industrial manufacture. Aside from promoting clean enenry, lightweight materials and composites are the most direct and effective way. For every 10\% drop in vehicle quality, fuel consumption will drop by $8 \%$ and emissions by $4 \%$. Among the lightweight materials, magnesium alloy and aluminum alloy stand out in low density, high intensity, machinability and recyclability. AZ31B magnesium alloy has been applied to aircraft wheel hub and car manufacturer. 5052 aluminum alloy performs well in formability and welding. One of the most chemical elements 5052 contains is Mg. Thus, AZ31B magnesium alloy and 5052 aluminum alloy can be connected in some ways [1, 2]..

Ultrasonic welding (USW) is different from other solid-state welding technology because of its high welding efficiency, short welding time, low heat input, and precision control [3-6]. Thus this technique is suitable for non-ferrous soft metals and their alloys, such as copper, aluminum, brass, gold and silver [7]. At high-power ultrasonic welding technology of AZ31B/A15052 dissimilar combinations, while the optimum joints were obtained through reasonable selection of sonotrode patterns and optimization of welding parameters. The joints with mechanical interlocking phenomenon and discontinuously distributed Mg17Al12 with low thickness could reach high tensile lap shear strength at $59.4 \mathrm{MPa}$ [8]. Researchers also observed that the strength of dissimilar joints was attained to be $35 \%$ higher with $\mathrm{Cu}$ interlayer than without $\mathrm{Cu}$ interlayer [9]. $\mathrm{Mg} / \mathrm{Al}$ (USW) joints 
welded with a $\mathrm{Zn}$ interlayer in-between displayed the maximum shearing strength about $89.6 \%$ greater than those of joints without a $\mathrm{Zn}$ interlayer [10]. These findings can improve mechanical property of $\mathrm{Mg} / \mathrm{Al}$ joints by higher power facilities or interlayer, meanwhile test cost increase. In the application of ultrasonic welding industry, a variety of parameters are generally used to optimize the parameters. Taking Emerson Branson as an example, the use of smearing additives and surface texture is more common[11].

As a result, many researchers commit themselves into seeking innovate and inexpensive ways to ultrasonic welding of dissimilar metals. The Fe-Al joints obtained with the textured steel were found to have up to $25 \%$ higher maximum tensile-shear load than the joints obtained with the untextured steel [12]. The surface roughness gradients on brass sheets are obtained directly by nanosecond laser texturing and found it is related to contact of material[13]. As a novel technique for fabricating surfaces with roughness and wettability gradients, it can be applied to chemical sensors and smart surfaces.

There has been little research on strengthening $\mathrm{Mg} / \mathrm{Al}$ different material joints of solid-state bonding by laser texturing before welding. In this study, an alternative welding approach to increase the bonding area between steel and aluminium alloy without modifying the laser-generated temperature profile is proposed and investigated. In this paper, an alternative seam welding approach to increase the bonding area between magnesium and aluminium alloy. A nanosecond pulsed laser is used for texturing the surface of magnesium and aluminium alloy prior to ultrasonic seam welding in order to locally increase the bonding area between these two dissimilar metals. At first, laser texturing was mainly used to increase the surface roughness of the roll, to lubricate the roll, and to extend its working life. In this process, the laser interacts with the surface material. The main mechanism is that the instantaneous, high-density energy generated by the laser on the surface of the material causes the heterogeneous metal on the surface of the material to melt and vaporize, making it in the form of gas. Escape the surface of the material. At the same time, the shock wave generated by the melting of the heterogeneous material causes the impurity particles not in the melting area to generate elastic potential energy, overcome van der Waals force and capillary force, and eject and break away from the surface of the material, thereby achieving the vibration peeling effect of the oxide film on the surface of the metal material. And leave pits on the surface of the material.The aim of this work is to select the optimum parameter and investigate impact of different laser generated textures on the mechanical properties (strength) of the $\mathrm{Mg}-\mathrm{Al}$ welds as well as to understand the mechanism of their formation.

\section{Experimental Procedure}

\subsection{Material}

Commercially available $1.0 \mathrm{~mm}$ thick sheets of 5052 aluminium alloy and $1.0 \mathrm{~mm}$ thick AZ31B magnesium alloy were used as base metals in the experiments. The magnesium and aluminium are $60 \mathrm{~mm}$ long and $20 \mathrm{~mm}$ wide. They were polished by $400 \#$ sandpaper and ultrasonic cleaned with alcohol. It aimed to remove impurities and oxides from material surfaces. Table 1 shows the chemical composition these two metals.

\subsection{Laser Texturing of Alloy}

The low power laser machining system is from RUNQIA ETLC. It is used to texture the mental. The controller contains RQM-0100 operating system providing a pulse to ejector with $\mathrm{f}=254 \mathrm{~mm}$ F-theta lens, and emit the pulse power of $100 \mathrm{~W}$, wavelength of $1064 \mathrm{~nm}$, Focusing spot diameter $\mathrm{D}$ of $50 \mu \mathrm{m}$. The parameter range of this device is shown in Table 3.

Table 1. Chemical composition of AZ31B Mg alloy and $5052 \mathrm{Al}$ alloy (wt-\%). 


\begin{tabular}{ccccccccc}
\hline material & Si & Fe & Cu & Mn & Zn & Cr & Al & Mg \\
\hline 5052 & 0.25 & 0.40 & 0.10 & 0.10 & 0.10 & 0.15 & rest & $2.2 \sim 2.8$ \\
AZ31B & 0.08 & 0.03 & 0.10 & $0.2 ~ 1.0$ & $0.6 \sim 1.4$ & 0.10 & $2.5 \sim 3.5$ & rest \\
\hline
\end{tabular}

Table 2 . Basic mechanical properties of AZ31B Mg alloy and A5052 Al alloy.

\begin{tabular}{cccc}
\hline \multirow{2}{*}{ material } & $\begin{array}{c}\text { Yield strength } \\
(\mathrm{MPa})\end{array}$ & $\begin{array}{c}\text { Ultimate tensile } \\
\text { strength }(\mathrm{MPa})\end{array}$ & Elongation $(\%)$ \\
\hline 5052 & 152 & 235 & 9 \\
AZ31B & 65 & 185 & 15 \\
\hline
\end{tabular}

Table 3 . Technical parameters of laser generator equipment

\begin{tabular}{cc}
\hline Device parameters & Parameter range \\
\hline Scan width & $0 \sim 80 \mathrm{~mm}$ \\
Laser power & $100 \mathrm{~W}$ \\
Laser wavelength & $1064 \mathrm{~nm} \pm 5 \mathrm{~nm}$ \\
Pulse frequency & $10-100 \mathrm{KHZ}$ \\
Scan speed & $\leq 6000 \mathrm{~mm} / \mathrm{s}$ \\
equipment power & $\leq 1500 \mathrm{~W}$ \\
power input & $220 \mathrm{~V}$ \\
\hline
\end{tabular}

The laser-induced craters were classified into grid and parallel line, which is decided by scanning mode. Besides, the diameter and depth of craters were influenced by scanning track and distance of laser beam (D), the distance from one spot to the center of another spot. Following the texture process, three different test textures (Fig 1) were fabricated on the surface of the mental. The ranges of texturing parameters are shown in Table 4 . Each texture of each mental was produced at least 5 coupons, providing a mass of samples for morphological observation, ultrasonic seam welding and tensile experiments.

Table 4. Experimental parameters of laser texture.

\begin{tabular}{ccccc}
\hline Texture & Track & $\mathbf{N}$ & $\mathbf{v}, \mathbf{m m} / \mathbf{s}$ & $\mathbf{D}, \boldsymbol{\mu} \mathbf{~ m}$ \\
\hline A & grid & 40 & 6000 & 0.1 \\
B & line & 40 & 6000 & 0.4 \\
C & line & 40 & 6000 & 0.1 \\
\hline
\end{tabular}

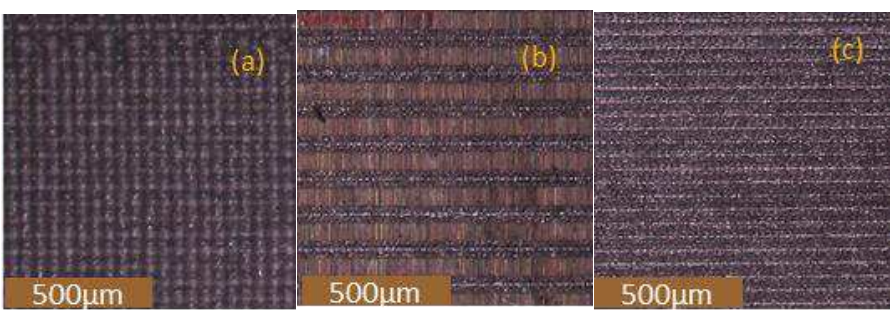

Figure.1Test textures fabricated on the surface of mental. (a)Texture A; (b) Texture B; (c) Texture C 


\subsection{Ultrasonic Welding of Textured Al to $\mathrm{Mg}$}

After cleaning textured and the untextured surface of the mental, the AZ31B Mg actual connection area is $20 \mathrm{~mm} \times 4 \mathrm{~mm}$ shown in Fig 2(c). The textured surface of both the AZ31B and the 5052 was opposite positioned. According to the formula (1), when coefficient $k$, hardness of material $H(\mathrm{HV})$ and thickness of the workpeice $(\mathrm{mm})$ are known, the welding power $\mathrm{P}(\mathrm{W})$ is confirmed. Then the welding pressure $F(\mathrm{MPa})$ and welding amplitude A (m) can be generally speculated in the case of friction coefficient and vibration frequency $f(\mathrm{~Hz})$ known in formula (2) [14].

$$
\begin{gathered}
P=k H^{3 / 2} \delta^{3 / 2} \\
P=4 \mu S F A f
\end{gathered}
$$

The ranges of welding parameters involved in the experiment are shown in Table 4.The $\mathrm{Mg} / \mathrm{Al}$ USW joints were manufactured using an ultrasonic welder system (MW2040) with a maximum energy of $4000 \mathrm{~J}$ and a frequency of $20.0 \mathrm{kHz}$ (Fig 2(a)). The tip of the sonotrode was $40 \mathrm{~mm}$ long and $4 \mathrm{~mm}$ wide. The surface of sonotrode patterns were composed of rectangular-pyramid-shaped teeth (Fig 2(b)).

Table 4. This is a table. Welding parameters of ultrasonic welding

\begin{tabular}{ll}
\hline & Specific instructions \\
\hline Welding energy/J & $500 、 1000 、 1500 、 2000$ \\
Vibration amplitude level & $55 \% 、 60 \% 、 65 \% 、 70 \%$ \\
Pressure/MPa & $0.1 、 0.2 、 0.3 、 0.4$ \\
\hline
\end{tabular}

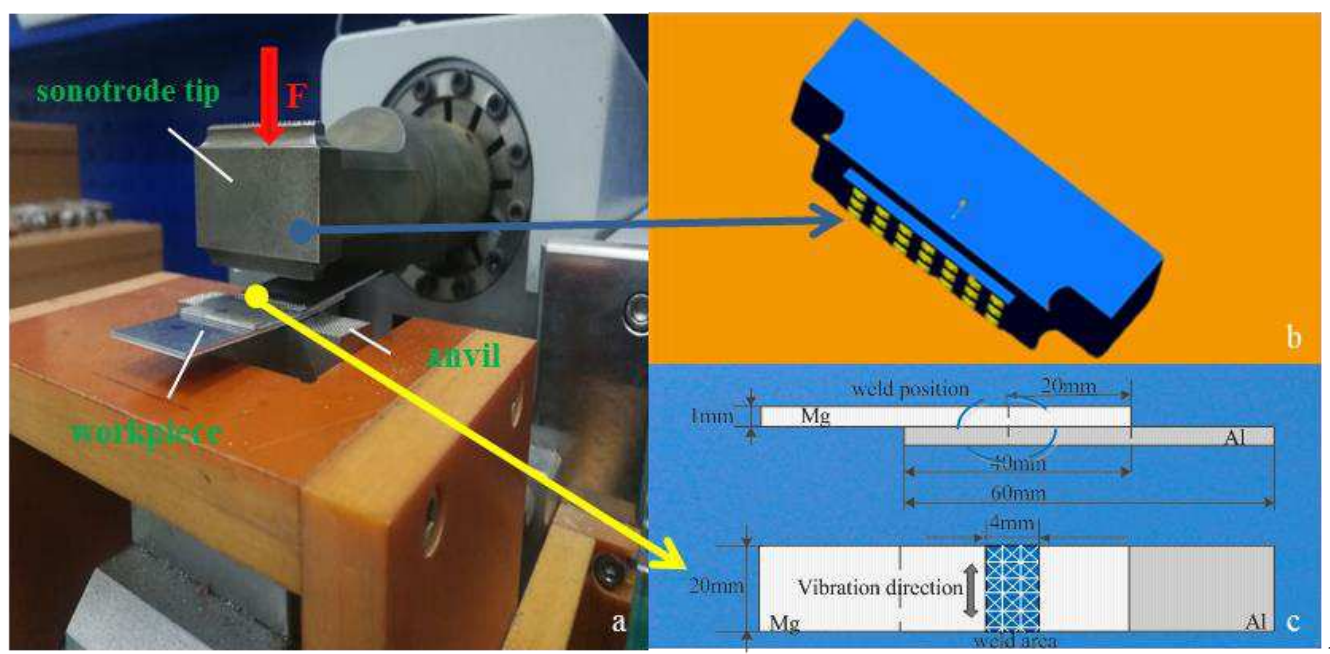

Figure 2. $\mathrm{Mg}$ and $\mathrm{Al}$ sample dimensions and experimental overlap: (a) components of ultrasonic

The AZ31B/ 5052 joints were produced at least 5 sample at the same welding parameters. Each 3 sample were applied to the tensile-shear tests by $200 \mathrm{kN}$ MJDW-200B microcomputer controlled electronic universal testing machine, the experiments carried out with constant cross-head speed of $1 \mathrm{~mm} / \mathrm{min}$ and at room temperature. One was used to observe the microstructure of fracture using type microscope. The interface 
morphologies of joints were obtained using an optical microscope (LeicaDM4M) and scanning electron microscope (SEM).

\section{Results and Discussion}

\subsection{Selection of Textured Pattern and Optimization of Welding Parameters}

The mechanical properties of the ultrasonic beam welding joints depend on the welding parameter to a great extent. In this paper, the effects of amplitude levels, pressure and welding energy during process of $\mathrm{Mg} / \mathrm{Al}$ joints were discussed. The lap shear test results of $\mathrm{Mg} / \mathrm{Al}$ joints are shown in Fig 3. When the amplitude level is $55 \%$, the maximum tensile load increased at $0.2 \mathrm{MPa}$ in Fig 3(a). The tensile lap shear strength originally increased, reached a peak value about 1300J and then decreased with increasing welding energy at $0.25 \mathrm{MPa}$ and $0.3 \mathrm{MPa}$. The excessive pressure made more frictional motion between the sonotrode and workpiece resulting into AZ31B crash, which leads to low tensile load at high pressure. The maximum tensile load was obtained at $0.1 \mathrm{MPa}$ pressure, $65 \%$ amplitude level due to unstable pressure in the air compressor in Fig 3(b). In general, the tensile load increased with higher pressure and higher amplitude level. Increasing the welding energy can increase welding time to ensure contact of material. While exorbitant input made the sonotrode press into AZ31B even leads to breakage at $70 \%$ amplitude level, 1600 energy and 0.3MPa pressure in Fig 3(c). When amplitude level is $60 \%$ and energy at 1600J, the tensile load of the joint were better. At 0.3MPa pressure and 1600 J energy, the maximum load was obtained at $55 \%$ amplitude. According to three welding parameters, the best lap shear load of the $\mathrm{Mg} / \mathrm{Al}$ joints can be obtained at $55 \%$ amplitude, 1600J energy and $0.3 \mathrm{MPa}$ along with the best accuracy.
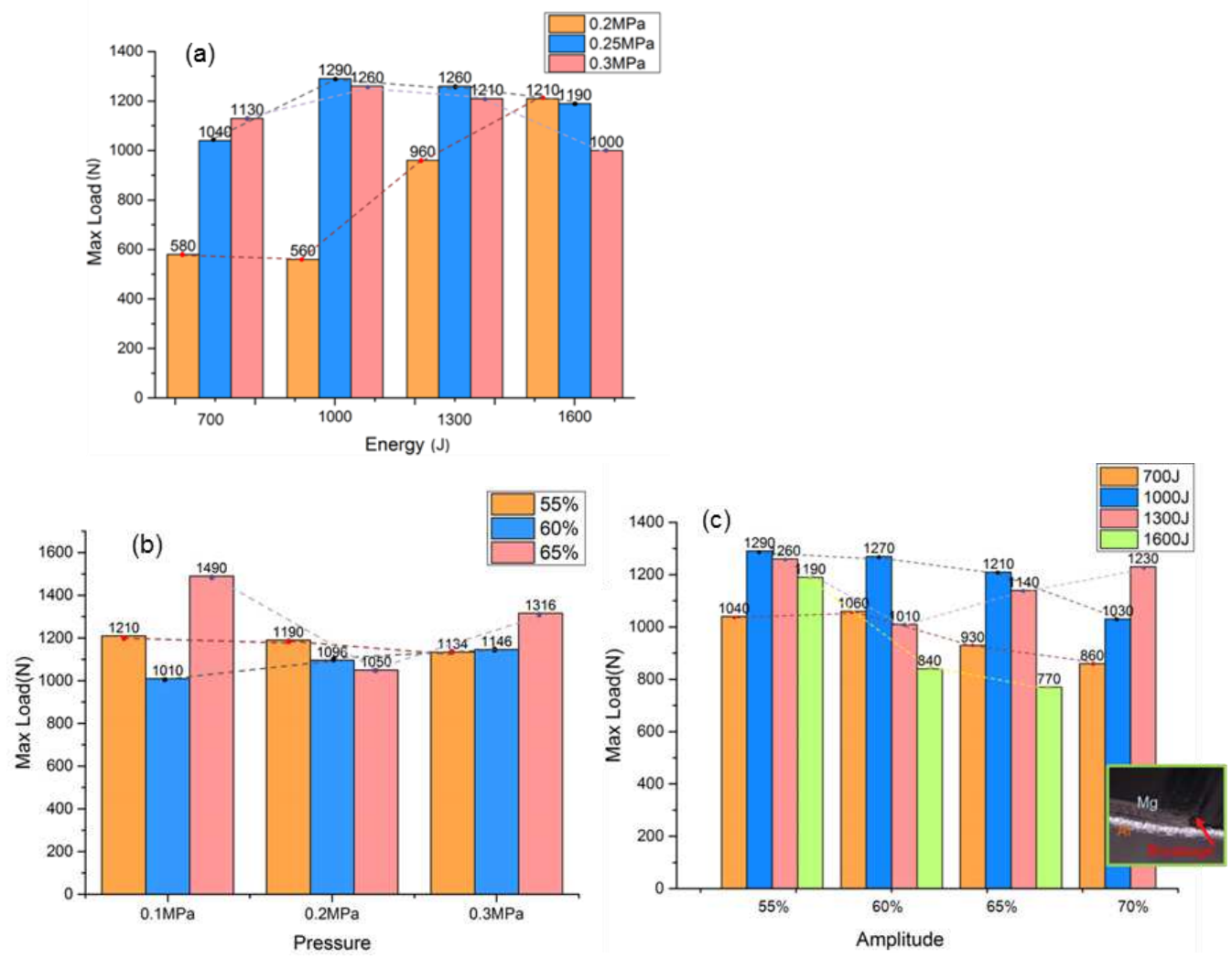

Figure 3. Shear tensile load of $\mathrm{Mg} / \mathrm{Al}$ ultrasonic welding joints produced with different amplitude levels pressure and welding energy: (a) at the pressure $0.3 \mathrm{MPa}$.

It is seen that the strength of $5052 \mathrm{Al}-\mathrm{AZ} 31 \mathrm{BMg}$ dissimilar joint with laser textured before was $26 \%$ higher than that without textured. This would suggest that the bonding of textured $\mathrm{Mg} / \mathrm{Al}$ interface was superior to that of untextured interface, due to the clearer 
surface, along with the rolling interface line. It is clear that the addition of texturing significantly increased the tensile lap shear load, especially texture A, primarily as a result of the rolling interface line.

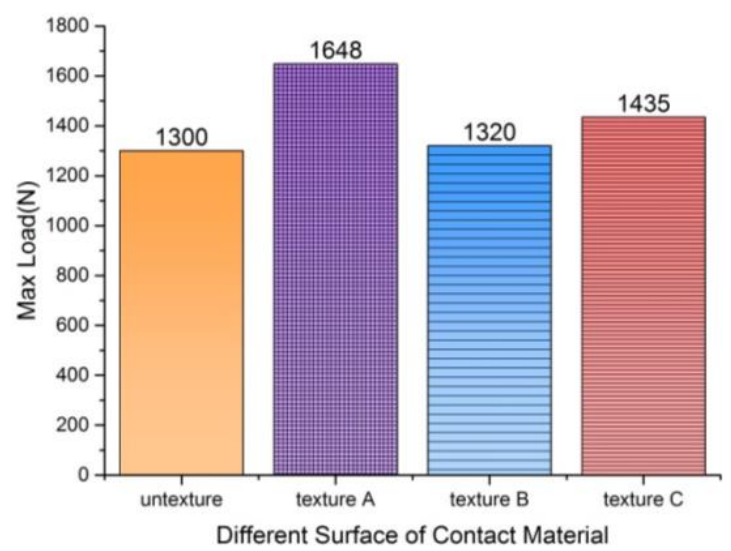

Figure 4. Comparison of tensile lap shear strength of $\mathrm{Mg} / \mathrm{Al}$ dissimilar joints with different surface of contact material

In the results of texturing, more intensive distribution on the surface, higher shear strength was achieved. This has resulted in better lubrication effect due to more channel to promote the flow of materials[15]. Fig. 4 reflects the shear performance of the joints with different contact surfaces. It can be seen from the figure that when the texturing pattern A is used, the best shear performance of the joint is $1648 \mathrm{~N}$. There are obvious cracks and material adhesion phenomena on the shear surface of the fracture. The furrows produced by the material texture morphology in the welding area are all filled with molten material, and the texture morphology cannot be distinguished. There is not much difference between the strength of the joint between the morphology $B$ and the untextured material. Combining the fracture morphology of the joint with the texture B in Figure 5 (b) and (e), it can be found that the friction between the $\mathrm{Mg}$ material and the $\mathrm{Al}$ material is not sufficient at this time. The indentation of the anvil is obvious, the morphology of the $\mathrm{Mg}$ side is obvious, the material does not undergo obvious plastic deformation and flow during the welding process, the $\mathrm{Mg}$ and $\mathrm{Al}$ are not fully contacted and combined, and the material does not form a good joint. The texturing morphology $\mathrm{C}$ increases the strength of the material joint by about $10 \%$, and there is no obvious tearing or material adhesion on the material surface, as shown in Figure 5 (c) and (f), but the texturing morphology of the fracture surface is not clear. It shows that a certain degree of plastic deformation has occurred on the surface of the material, but the material combination is still insufficient. 


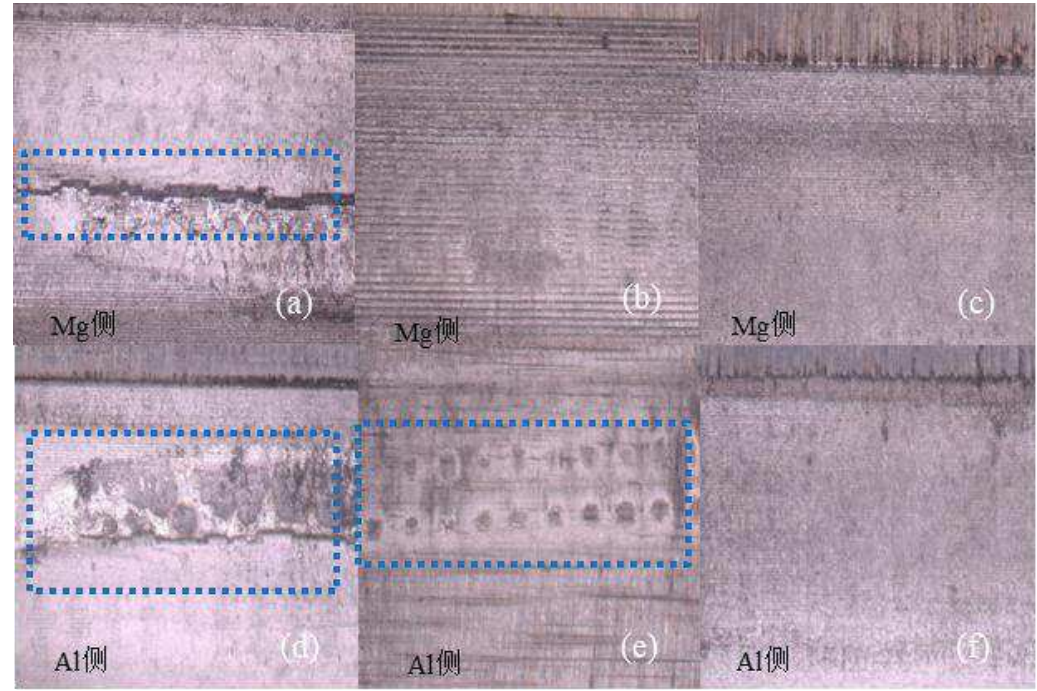

Figure 5. macroscopic morphology of fracture under different laser texturing morphologies

The magnified observation of the Mg side joint fracture of the texturing morphology $\mathrm{C}$ shows the micro morphology shown in Figure 6. From Figure (a), it can be seen that the surface of the texturing material is parallel to the ravine, Figures (b), (c) They are different morphologies far from the center of the fracture and close to the center of the fracture. It can be seen that after the laser texturing method is used to process the material, while pits appear on the surface of the material, the molten metal impacted by the laser will condense on the metal surface again. Because the laser spots are closely arranged, the molten metal is also connected into a strip. Straight line, and the molten metal surface area is larger near the spot, and the melting area between the spot gaps is smaller. Under the same magnification, the pits at the edge of the fracture are more clean, and the area of molten metal on both sides is smaller, while the pits near the center of the fracture are not clear, and there are more metal debris on the surface. It may be the stress concentration of the $\mathrm{Mg}$ material in the welding center, the material flow is obvious, and the Al material that flows after contact with the $\mathrm{Al}$ material re-integrates into the pits, and the molten material at the ridges and protrusions is shattered by the friction of the welding process, leaving fragments on the surface of the material. Crumbs. After magnifying I in figure (a), we get figure (d). It can be found that the gullies in figure (a) are not continuously distributed. After magnification, it is found that the fat bumps of the pits are not as shown in figure (b), (c) Clear, but there are obvious friction marks, indicating that during the welding process of $\mathrm{Mg}$ and $\mathrm{Al}$ materials, the material stress distribution at the edges is not uniform, only the textured bumps are in contact, and during the shearing experiment, The $\mathrm{Mg}$ material adheres to the $\mathrm{Al}$ material, forming scratches on the surface of the $\mathrm{Mg}$ material. 


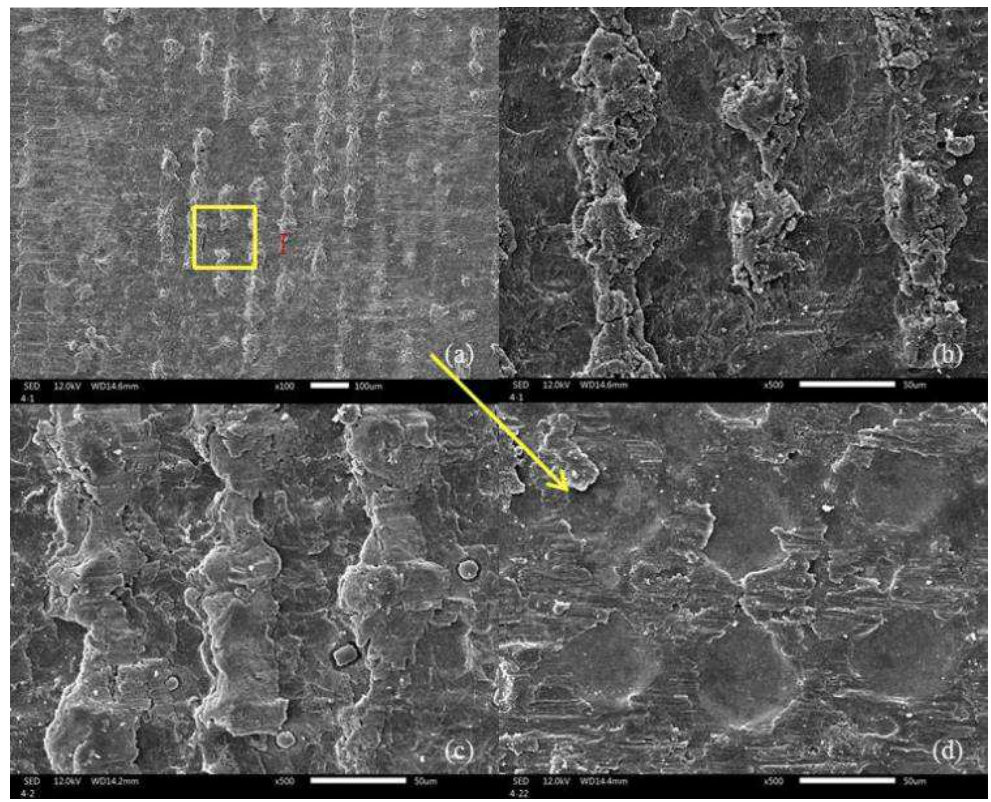

Figure 6. micro morphology of the fracture surface after laser texturing

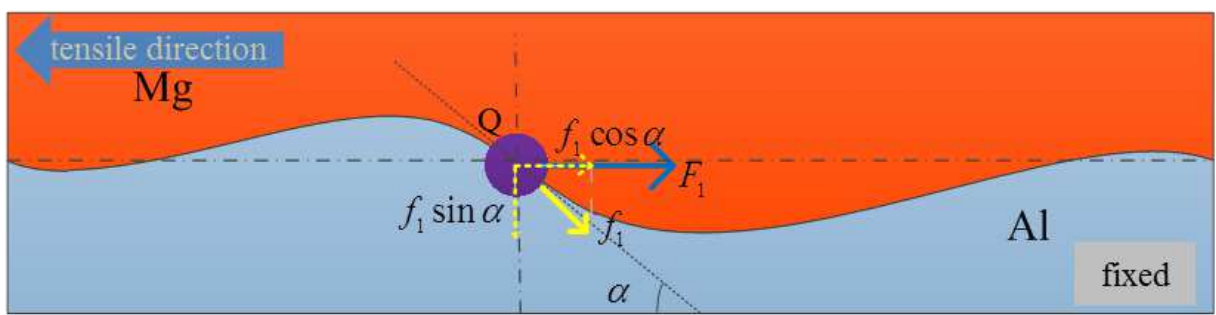

Figure 7. Mechanical analysis of particle on contact surfaces

A mass point $Q$ was chosen to analyze force situation shown in Fig 7. As $5052 \mathrm{Al}$ was clapped and AZ31B Mg pulling up, the point received both resistance by $5052 \mathrm{Al}$ and friction due to relative motion between materials. The angle formed by the tangent of the contact surface at the point indicates the friction direction. Before laser texture, the tensile lap shear strength was calculated by:

$$
\sigma=\frac{F}{S_{Q}}
$$

The shear force is measured by universal testing machine, is the area of point. After laser texture, the tensile lap shear strength was calculated by:

$$
\boldsymbol{\sigma}=\frac{F^{\prime}}{S_{Q}}
$$

$S_{Q}$ is the as the same as it in formula (3), while $F^{\prime}>F$ because of:

$$
F^{\prime}=F_{1}+f \cos \alpha
$$

Thus, $\sigma^{\prime}>\sigma$ can be inferred, which may explain laser textured material get better mechanical properties.

\subsection{Surface morphology and cleaning effect of laser texture}

217

As can be seen from Fig.8(a), the surface was covered with the impurities and oxides, which impede the combination of materials. Pulsed laser can breakdown the oxides effectively especially in aluminum alloy[16]and crater left on the surface in Fig.8(b). The 
overflow of hydrogen may lead to the ring crater[17]. The melting pool was produced by laser beam and adjusted by the processing parameters. It contains fewer impurities impulse by laser than no-cleaning surface.

(a)

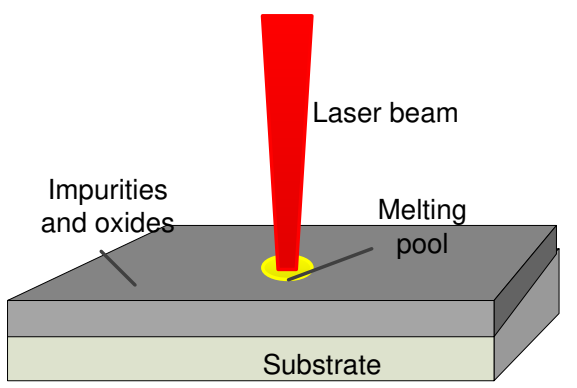

(c)

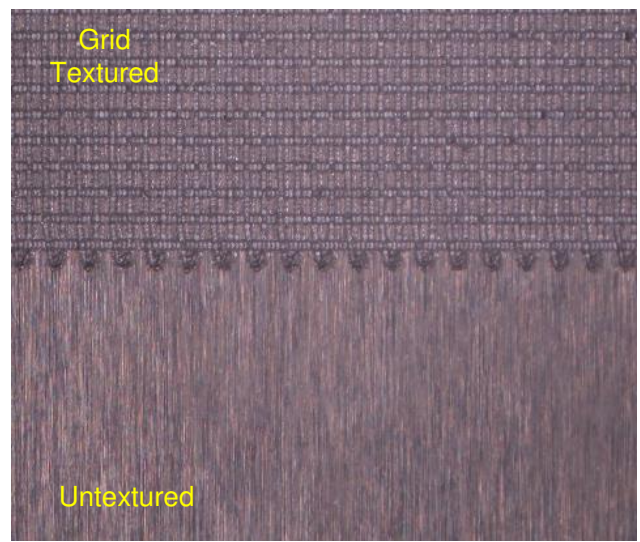

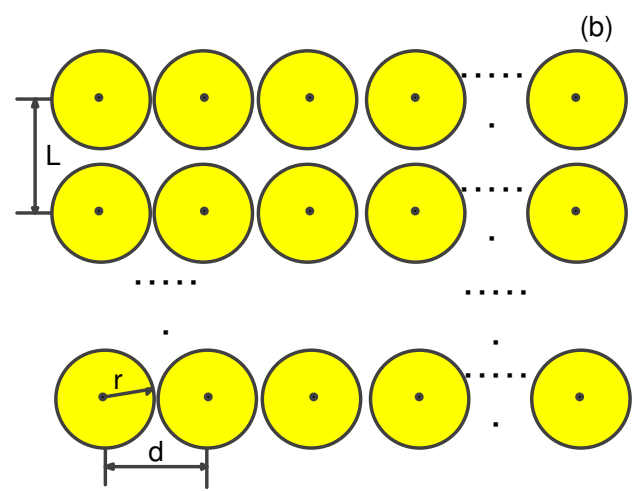

(d)

Figure 8. Mechanism of laser texture: (a) process of laser texturing; (b) scanning track of line texture; (c) comparison of textured and untextured surfaces; (d) scanning track of grid texture

Scanning track of line texture is shown in Fig 8(b). The yellow circle represents the spots that make up the track. Under the action of the $X$ galvanometer, the pulsed spot will transform from a point spot to a linear arrangement. On this basis, when the spot arrangement reaches the boundary of the selected area, due to the deflection of the $Y$ galvanometer, another linear arrangement parallel to it will be formed in space. The distance between the two lines after deflection is the longitudinal distance of the line $\boldsymbol{L}$, $\boldsymbol{d}$ is the lateral distance of the spot, $\boldsymbol{r}$ is the radius of the laser texturing spot, and is the longitudinal distance of the spot. It is clearly shown that obvious staggered morphology is formed on the surface of the material in fig 8(c). When it turns into grid texture, the laser transmitter emits laser in $\mathrm{X}$ direction at the first time and turns to $\mathrm{Y}$ direction in second time. The coverage of the spot $c$ on the surface of the material can be calculated by formula (6).

$$
c=\frac{S_{l}}{S}
$$

Where $c$ is the coverage rate, $S_{l}$ is the spot area, and $S$ is the scanning area. According to formula (6) to calculate the coverage of the three topography, it can be seen that the coverage of the parallel line topography [18]:

$$
\mathbf{c}_{\text {line }}=\frac{\mathrm{Ng} 2 f_{c} \mathrm{~g}^{2} \mathrm{r}^{2}}{\mathbf{W g}\left[2 f_{\mathrm{c}} \mathrm{g} 2 \mathrm{r}+\left(2 \mathrm{f}_{\mathrm{c}}-1\right) \mathrm{gl}\right]}
$$


In the formula (7), $\boldsymbol{N}$ is the number of horizontal spots, $\boldsymbol{W}$ is the width of laser texturing, and $f_{c}$ the frequency of the one-dimensional galvanometer. The number of horizontal spots per unit time is equal to $2 f_{c}$. Considering that the laser scanning speed $v$ is uniform, and in a unit time, the number of spots appearing in laser scanning is the same as the pulse frequency $f$, then:

$$
\begin{aligned}
N & =\frac{f}{2 f_{c}} \\
l & =\frac{v}{f_{c}}
\end{aligned}
$$

Substituting formula (8) and (9) into formula (7), formula (10) can be obtained:

$$
c_{\text {line }}=\frac{N \mathrm{~g} 2 f_{c} g \pi r^{2}}{W g\left[4 f_{c} g r+2 v-\frac{v}{f_{c}}\right]}
$$

For topography B and topography $\mathrm{C}$, they share the same texture width $W$, spot size and scanning speed $v$. The coverage $c$ is only related to the frequency of the onedimensional galvanometer $f_{c}$. According to the monotonicity of the function, it can be seen that due to the monotonicity of function. The frequency of texture B is larger, so $C_{B}<$ $C_{C}$. In the texturing area of the same size, the light spot area caused by the grid morphology is significantly larger than the line morphology, therefore $C_{B}<C_{C}<C_{A}$. It is found that the coverage rate of the topography A is the largest, and the better removal effect of oxide film can be obtained. Therefore, the mechanical properties obtained by morphology A are the best.
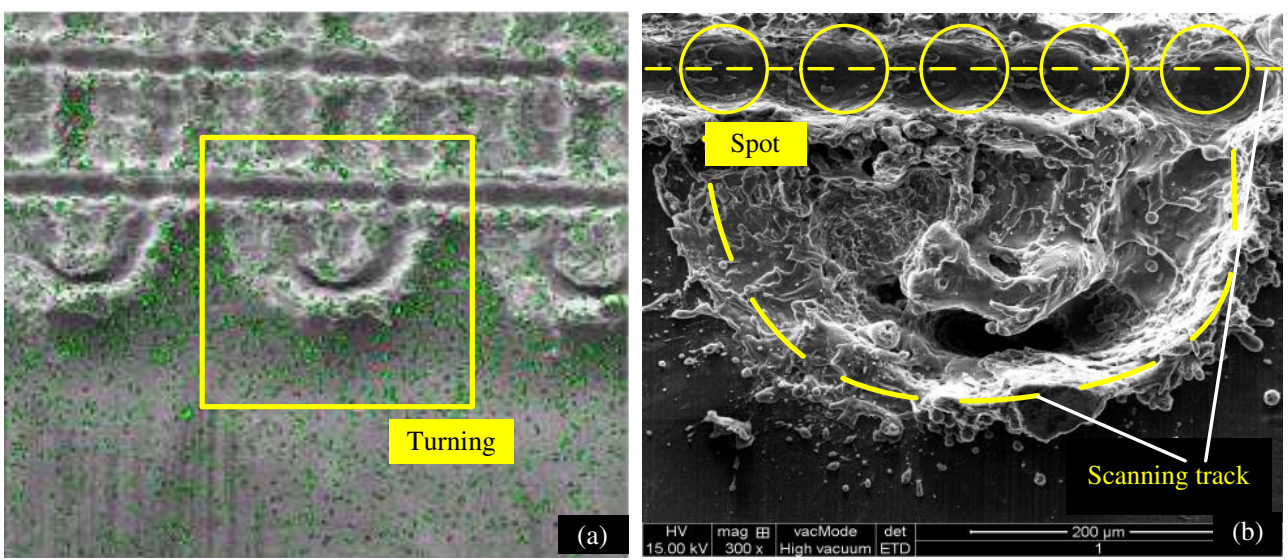

Figure 9. Chemical analysis of the grid textured surface: (a) Oxygen element distribution on textured surface; (b) micro morphology at the turning

Fig. 9 (a) is the image of the region A in Fig. 8(a) after magnification of 200 times by SEM. The semicircular trace in the Fig.9(b) is the turning point of the laser track, and the green dot is the detected oxygen element. Fig.8(a) clearly shows that in the upper half of the laser-textured material surface, there are fewer oxygen elements attached. While in the untextured part, oxygen elements are evenly distributed on the surface of the material and densely distributed at the laser turning point. It may be that the temperature at the turning point is so high that caused thermal processing and oxidation on the surface. The molten metal reacts with oxygen in the air, and the oxygen content on the surface of the material decreases and then increases. This caused the turning edge and overlapping area of track containing more oxygen content than untextured surface. The spot was difficult to be observed at the turning as shown in Fig.9(b) due to collective effect of both $X$ galvanometer and $Y$ galvanometer. 
According to previous studies[19], the contact between materials usually occurs at the small order of magnitude. Once the material contacted with each other, the irreversible plastic deformation and fracture happened. Therefore occur in a stochastic manner in the rapidly changing points of the surface. The processes in micro contacts giving rise to irreversible changes of the surface topography are plastic deformation, detaching of wear particles and their reintegration into the surfaces in Fig 10. Plastic deformation leads to a mass transport along each surface, while the detaching and reintegration processes lead to a mass transfer between the contacting surfaces. Both processes can be macroscopically modeled as a stochastic transport of material either along the surface or to and from the surface. This picture of a stochastic mass transport can be used as a basis for a simple phenomenological model of processes leading to changes in surface topography.

Untexture
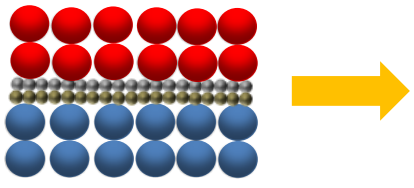

Detaching of wear particles

Reintegration
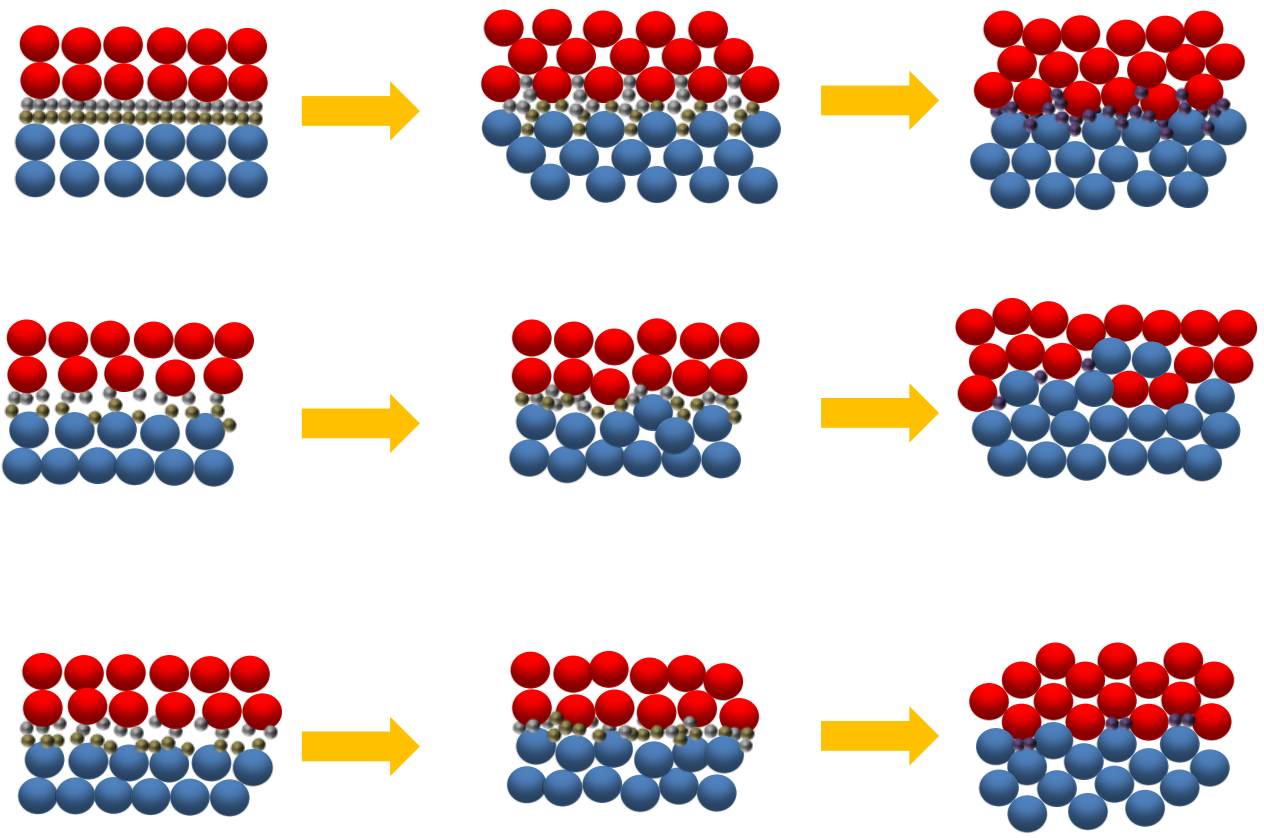

Figure 10. Development of surface topography

From a microscopic point of view, when the $\mathrm{Mg}$ material and the Al material are very close, the $\mathrm{Mg}$ atoms and $\mathrm{Al}$ atoms start to contact, resulting in atomic contact surfaces. These contact surfaces are called "bridges". The total contact area of the bridge is the actual contact of the material.

As shown in Fig. 11, the occlusion of the contact interface can be regarded as the result of the interlaced contact of material atoms. The diffusion mechanism of atoms in solid solution is mostly vacancy diffusion, when the welding machine applies pressure in the interstitial solid solution of $\mathrm{Mg}$ atoms, the atomic diameter of $\mathrm{Al}$ atoms (diffusion atoms) is relatively small, and they occupy interstitial positions, where they can easily migrate from one position to another, thereby forming interatomic bonds. The welded joint was observed under an ESEM environmental scanning electron microscope with a magnification of 300 times, and as shown in Fig.12(a), the contact interface of the untextured ultrasonic welding joint was a nearly straight line, and the biting was not obvious. The material contact interface after the texturing morphology A has formed a clear occlusal morphology.

As shown in Fig. 12(b), the $\mathrm{Mg} / \mathrm{Al}$ bite is obvious, and the pits on the material surface due to texturing are filled with each other. When the $\mathrm{Mg}$ material is subjected to the normal pressure of the welding machine, due to the different lateral shrinkage between the materials, frictional movement occurs between the magnesium and aluminum. When 
two materials come into contact, the first layer of material will be plastically deformed. At this time, the particles on the top layer of the material surface will fall off due to wear. As the anvil continues to press down, these particles will reintegrate into the material surface. For untextured materials, the surface metal oxide is approximately thick. When the welder anvil is pressed downward, the high-frequency ultrasonic vibration cannot completely crush the oxide[20].

Therefore, when the joint is formed, the desorption and remelting of the metal oxide particles occur before the metal atoms contact, which hinders the combination of dissimilar metal elements. As shown in Fig. 12(c), the green oxygen element is distributed at the material contact interface.

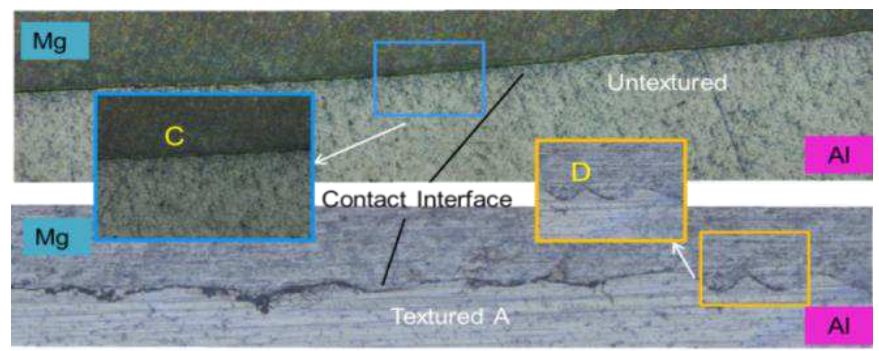

Figure 11. Contact interface of joint

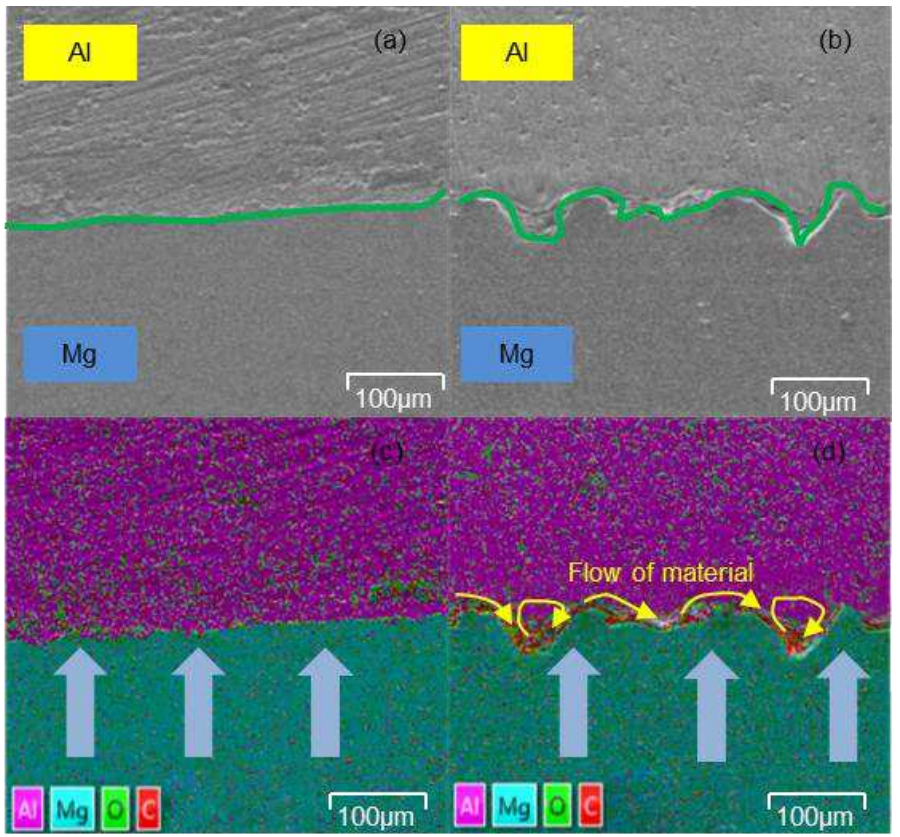

Figure 12. Contact interface of joint: (a) untextured $\mathrm{Mg} / \mathrm{Al}$ contact interface; (b) textured $\mathrm{Mg} / \mathrm{Al}$ contact interface; (c) distribution of elements in the untextured $\mathrm{Mg} / \mathrm{Al}$ contact interface; (d) distribution of elements in the textured $\mathrm{Mg} / \mathrm{Al}$ contact interface

On the textured material, the metal oxide on the surface is reduced by laser erosion, and the forming special morphology promotes the contact between $\mathrm{Mg}$ atoms and $\mathrm{Al}$ atoms. It can be seen from Fig. 12(d) that when the anvil is pressed down, the pits of the magnesium material texture are filled with aluminum, and the protrusions at the edges of the pits are squeezed against the aluminum, forming a mosaic shape. It is not difficult to find the presence of element $C$ at the junction of the two materials, indicating that holes are formed when the two materials flow and remelt, leading to the filling of the mosaic material.

\section{Conclusions}


In this study, the high-quality joint of textured AZ31B Mg/5052 Al was successfully achieved by ultrasonic welding. The influence of laser texture on the microstructure and mechanism of AZ31B / 5052 joint connected by ultrasonic welding was investigated in the way of mechanical analysis of particle and movement of material atoms. The patterns of laser texture in this study were arranged evenly without overlapping. The main results of this work included as follow:

1. The optimum tensile strength for the $\mathrm{Mg} / \mathrm{Al}$ joint was obtained at $1600 \mathrm{~J}$ welding energy, 55\% amplitude level, and $0.3 \mathrm{MPa}$ pressure. The optimum shear load of the $\mathrm{Mg} / \mathrm{Al}$ joint was about $1300 \mathrm{~N}$ with untextured surface.

2. Laser texture can remove the oxide layer on the surface of material effectively. The tensile shear strength of adhesive bonded joints was increased $26 \%$ after grid texturing. Grid texture owns the highest coverage rate, which leads to the best cleaning effect to form the vortex-like structure.

3. Rough surface contains many channels which revealed hydrophilicity can improve material flowage significantly. Obvious vortex-like structure was shown at the joint interface. The bonding mechanism of $\mathrm{Mg} / \mathrm{Al}$ joints was inferred as metallurgical bonding characterized mechanical locking.

Author Contributions: Methodology, validation, formal analysis, and writing-original draft prepa- ration, C.W.; con-ceptualization, resources, funding acquisition, and writing-review and editing, Y.F.; investiga- tion and data curation, J.H.; visualization, supervision,project administration, J.L. and S.Z.; All authors have read and agreed to the published version of the manuscript.

Funding: The Natural Science Foundation of Shanghai (Grant No. 20ZR1422600) has in part supported the research.

Data Availability Statement: Not applicable.

Acknowledgements: The authors would like to acknowledge the other members of the research team for their assistance during the experimental testing process.

Conflicts of Interest: The authors declare that they have no known competing financial interests or personal relationships that could have influenced the work reported in this paper.

\section{References}

1. U.F.H. Suhuddin, V. Fischer, A. Kostka, J.F. dos Santos, Microstructure evolution in refill friction stir spot weld of a dissimilar Al-Mg alloy to Zn-coated steel, Sci. Technol. Weld. Join. 22 (2017) 658-665.

2. J.F. Nie, Y.M. Zhu, J.Z. Liu, X.-Y. Fang, Periodic segregation of solute atoms in fully coherent twin boundaries, Science (80-.). 340 (2013) 957-960.

3. Li X, Tian H, Wang T, Zhang S (2018) Effect of ultrasonic transducer structure on friction plasticizing heating rate under the longitudinal vibration excitation Microsystem Technologies

4. G.He,Y.Zhao,B.Gan,X.Sheng,Y.u.Liu,L.Tan,Mechanismofgrainrefinementin an equiatomic medium-entropy alloy CrCoNi during hot deformation, J. Alloys Compd. 815 (2020) 152382,https://doi.org/10.1016/j.jallcom.2019.152382.

5. S. Zhang, Y. Zhao, X. Cheng, G. Chen, Q. Dai, High-energy ultrasonic field effects on the microstructure and mechanical behaviors of A356 alloy, J. Alloys Compd. 470 (1-2) (2009) 168-172, https://doi.org/10.1016/j.jallcom.2008.02.091.

6. Neppiras EA. Ultrasonic welding of metals. Ultrasonics 1965;7-10:128-35.

7. Annoni M, Carboni M. Ultrasonic metal welding of AA6022-T4 lap joints: Part I - Technological characterization and mechanical behavior. Sci Technol Weld joining 2011;16(2):107-15.

8. Feng M-N, Luo Z (2018) Interface morphology and microstructure of high-power ultrasonic spot welded Mg/Al dissimilar joint Science and Technology of Welding and Joining 24:63-78 doi:10.1080/13621718.2018.1483598 
9. Xie J, Zhu Y, Bian F, Liu C (2017) Dynamic recovery and recrystallization mechanisms during ultrasonic spot welding of Al-Cu-Mg alloy Materials Characterization 132:145-155 doi:10.1016/j.matchar.2017.06.018

10. Gu X, Sui C, Liu J, Li D, Meng Z, Zhu K (2019) Microstructure and mechanical properties of Mg/Al joints welded by ultrasonic spot welding with Zn interlayer Materials \& Design 181 doi:10.1016/j.matdes.2019.108103

11. H. Peng, X. Jiang, X. Bai, D. Li, D. Chen, Microstructure and mechanical properties of ultrasonic spot welded Mg/Al alloy dissimilar joints, Metals (Basel) 8 (2018) 229.

12. Pardal G, Meco S, Dunn A, Williams S, Ganguly S, Hand DP, Wlodarczyk KL (2017) Laser spot welding of laser textured steel to aluminium Journal of Materials Processing Technology 241:24-35 doi:10.1016/j.jmatprotec.2016.10.025

13. Ta VD et al. (2016) Laser textured surface gradients Applied Surface Science 371:583-589 doi:10.1016/j.apsusc.2016.03.054

14. LI Yajiang. Special connection technology[M]. Beijing:Ma-chinery Industry Press, 2007, 209-210.

15. Won SJ, Kim HS (2019) Effects of laser parameters on morphological change and surface properties of aluminum alloy in masked laser surface texturing Journal of Manufacturing Processes 48:260-269 doi:10.1016/j.jmapro.2019.10.034

16. Shi T, Wang C, Mi G, Yan F (2019) A study of microstructure and mechanical properties of aluminum alloy using laser cleaning Journal of Manufacturing Processes 42:60-66 doi:10.1016/j.jmapro.2019.04.015

17. Feng $\mathrm{Z}$ et al. (2019) Effect of laser texturing on the surface characteristics and bonding property of $30 \mathrm{CrMnSiA}$ steel adhesive joints Journal of Manufacturing Processes 47:219-228 doi:10.1016/j.jmapro.2019.09.046

18. Laser Cleaning Process of 2219 Aluminum Alloy Anodic Oxide Film Before Welding (2019) Chinese Journal of Lasers 46:0102005

19. Ilie F (2018) Diffusion and mass transfer mechanisms during frictional selective transfer International Journal of Heat and Mass Transfer 116:1260-1265 doi:10.1016/j.ijheatmasstransfer.2017.09.083

20. Popov VL, Psakhie SG (2007) Numerical simulation methods in tribology Tribology International 40:916-923 doi:10.1016/j.triboint.2006.02.020 